\title{
Active sharing of a novel, arbitrary innovation in captive cotton-top tamarins?
}

\author{
Samin Gokcekus ${ }^{\mathrm{a}, *}$, Rahel K. Brügger ${ }^{\mathrm{b}}$ and Judith M. Burkart ${ }^{\mathrm{b}}$ \\ ${ }^{\text {a }}$ Edward Grey Institute of Field Ornithology, Department of Zoology, University of Oxford, \\ Oxford OX1 3PS, UK \\ ${ }^{\mathrm{b}}$ Department of Anthropology, University of Zurich, Zurich, Switzerland \\ *Corresponding author's e-mail address: samingokcekus@gmail.com
}

Received 17 August 2020; initial decision 9 September 2020; revised 8 October 2020; accepted 2 November 2020; published online 14 December 2020

\begin{abstract}
Most cultural behaviours in primates stem from innovations that are beneficial since they provide access to food or comfort. Innovations that are seemingly purposeless and arbitrary, and nevertheless spread through a social group, are rarer but particularly relevant to understanding the evolutionary origin of culture. Here, we provide an anecdotal report of a series of non-instrumental woodchip manipulation and modification events in captive cotton-top tamarins. Intriguingly, woodchips were preferentially manipulated in a position that was readily visible to a partner in a different enclosure, and the innovation apparently spread to other individuals. Together, this suggests that the arbitrary innovation was actively shared with a conspecific, which is consistent with the pattern of transmission of another arbitrary innovation in cotton-top tamarins, namely stick-weaving.
\end{abstract}

\section{Keywords}

cotton-top tamarins, innovation, object manipulation, social learning, captivity effect, object showing, information donation.

\section{Introduction}

Traditions or cultural behaviours (often used interchangeably; Whiten \& van Schaik, 2007) are an integral part of many primates' behavioural repertoires and have been studied for decades (e.g., chimpanzees: Whiten et al., 1999, 2001; orangutans: van Schaik et al., 2003; Wich et al., 2012; capuchins: Perry 
et al., 2003; Ottoni \& Izar, 2008; spider monkeys: Santorelli et al., 2011). Cultural behaviours, or variants, are defined as socially learned innovations (van Schaik et al., 2003) and usually spread passively through groups via social learning (Hobaiter et al., 2014). Their presence in nonhuman primates provides an important window into the evolution of culture, in particular when innovations are arbitrary and social transmission is facilitated through information sharing, scaffolding, or even teaching (Castro \& Toro, 2014; Caldwell et al., 2018; van Schaik et al., 2019).

Primates are known for their spontaneous innovative abilities in the wild as well as in captivity (e.g., Laidre, 2008; Huebner \& Fichtel, 2015; Amici et al., 2020). The factors influencing the propensity to innovate have long been debated, with conflicting evidence showing that brain size, age, sex and social status can influence who innovates (Reader \& Laland, 2001; Kendal et al., 2005; Navarrete et al., 2016). Great apes are known for their particularly large cultural repertoires that often involve food processing techniques, object manipulation or comforting behaviours. It is unsurprising that beneficial innovations that provide access to novel food sources or enhance comfort can spread easily through a social group thus providing the basis for cultural variation. More curious however, are arbitrary cultural variants that are apparently unproductive and without an obvious purpose, such as eye poking or hand sniffing in capuchins (Perry et al., 2003, 2017; Perry, 2011; see also Lonsdorf et al., 2016), hand clasp grooming and the 'grass-in ear behaviour' in chimpanzees (Bonnie \& de Waal, 2006; van Leeuwen et al., 2014; Wrangham et al., 2016, see also Bonnie et al., 2007), stone handling in Japanese macaques (Gunst et al., 2007; Leca et al., 2008, 2011), as well as stick-weaving in cotton-top tamarins (Snowdon \& Roskos, 2017). Some of these arbitrary cultural behaviours seem to have social functions (Perry, 2011; Wrangham et al., 2016), but others, such as the 'grass-in ear behaviour' or stick-weaving do not. The latter behaviour is performed by tamarins and consists of breaking small twigs from branches and weaving them through the mesh of the enclosure. Even though this behaviour doesn't provide access to food, comfort, or any other benefit, it is socially transmitted and appears to even be shared actively (Snowdon \& Roskos, 2017; for other instances of information donation in tamarins, see also Rapaport \& Ruiz-Miranda, 2002; Rapaport, 2011; Troisi et al., 2018, 2020).

Here we report a similar and equally arbitrary behavioural pattern as the stick-weaving described by Snowdon \& Roskos (2017), namely a series 
of non-instrumental object manipulation events (after Leca et al., 2011) in cotton-top tamarins that included object modifications of woodchips. Woodchips are part of the standard home enclosure floor covering (bark mulch) in this colony, of about 80 common marmosets and 12 cotton-top tamarins. Individuals usually ignore the woodchips (especially common marmosets), lifting them only to look for food underneath. The woodchips are not edible and are never used in a productive way. Surprisingly, two cotton-top tamarins have been observed developing a strong interest in manipulating and even modifying these woodchips (shaving off one end of the woodchip with the teeth and creating a pointed end, see below). We provide a detailed description of the events involving woodchips over a period of 17 days where video footage was collected in two adjacent home enclosures housing two female cotton-top tamarins for an ongoing experiment. We describe repeated 'retrieve-show-manipulate' sequences (defined in Table 1 and shown in Figure 1) where one individual would retrieve a woodchip from the floor, show it to the conspecific by holding it up against the mesh dividing the two individuals, and then manipulate the woodchip; the conspecific would observe the majority of these sequences (91\%). Finally, we use detailed video analyses to verify that they indeed preferentially spent time at the contact mesh when they were manipulating the woodchip, but not when they were not doing so.

\section{Methods}

\subsection{Individuals and housing}

The individuals observed were two female, captive-born, mother-reared cotton-top tamarins (twins, age $=38$ months) living at the Primate Station of the Anthropological Institute and Museum of the University of Zurich, Switzerland. They were housed in two adjacent, bark mulch (woodchip) floored enclosures $\left(4 \mathrm{~m}^{3}\right)$ consisting of tree branches, baskets, boxes for sleeping, an infrared lamp, and a table (added for another ongoing experiment). These enclosures, E5 (housing individual 5, subsequently referred to as I5) and E6 (housing individual 6, subsequently referred to as I6), have partial visual access through a grid mesh separating the two enclosures. Prior to being temporarily housed individually for husbandry reasons, I5 and I6 were housed in the main tamarin enclosure (with the same woodchip flooring) with their parents and siblings $(N=5)$. After their initial removal, I5 and I6 
Table 1.

Operational definitions of each of the terms used to describe the individuals' behaviours.

\begin{tabular}{|c|c|}
\hline Behaviour & Operational definitions \\
\hline Watch & $\begin{array}{l}\text { The individual's face is oriented towards the target within an angle of } 45 \\
\text { degrees (to the left or right) of head rotation }\end{array}$ \\
\hline Retrieve & $\begin{array}{l}\text { The individual is on the ground and they use the hands to remove a woodchip } \\
\text { from the ground and take it at least three body-lengths away from its original } \\
\text { position }\end{array}$ \\
\hline Show & $\begin{array}{l}\text { The individual is within one body-length of the mesh separating E5 and E6; } \\
\text { the arms are extended upwards with the woodchip in one or both hands, the } \\
\text { woodchip is making physical contact with the mesh; it is not necessary for the } \\
\text { conspecific to be simultaneously watching, but this was the case in the } \\
\text { majority of cases }(91 \%)\end{array}$ \\
\hline Manipulate & $\begin{array}{l}\text { The individual's hands are in physical contact with the woodchip and one or } \\
\text { more of the following behaviours occurs }\end{array}$ \\
\hline Turn & Turning the woodchip over within one hand \\
\hline Pass & Passing the woodchip from one hand to the other \\
\hline Bite & $\begin{array}{l}\text { Biting the woodchip, this can occur in two ways: } \\
\text { - Single hand: holding the woodchip on one end and biting the other } \\
\text { - Both hands: holding the woodchip on each end with each hand and biting } \\
\text { out pieces of the middle }\end{array}$ \\
\hline Inspect & Looking closely at the woodchip \\
\hline Seesaw & $\begin{array}{l}\text { Holding the woodchip against the mesh (so that the centre is on one strand of } \\
\text { the mesh) and putting weight on either side of the woodchip }\end{array}$ \\
\hline
\end{tabular}

had occasional access to the main enclosure, but could not visit simultaneously. After a month and a half (at the beginning of June 2019), I5 and I6 could no longer visit the main enclosure and were housed in E5 and E6 with visual contact until they were paired with a new mate. The main enclosure was across the hall from E5 and E6; they had auditory but no visual contact with the main group.

\subsection{Context of observations}

We observed the woodchip manipulation during the administration of a curiosity task using two plexiglass panels $(70 \times 30 \mathrm{~cm})$ with various novel objects that the individuals had no prior experience with (Gokcekus, 2020). All data was collected in June-July 2019, after an initial two-week period of habituation. All testing was restricted to within three hours of the morning feed and each individual was exposed to the panel five times for $30 \mathrm{~min}$ utes. 


\subsection{Video coding and ethogram}

The behaviour of the subjects was coded from the videos using the operational definitions in Table 1.

To scrutinize whether the 'show' behaviour of I5 was an artefact of a general preference to sit on the perch close to the mesh that was visible to I6, we additionally quantified how much time I5 spent with vs. without a woodchip on (i) the perch of the contact mesh (the mesh at the border between E5 and E6), (ii) an identical perch on the front mesh, or (iii) in any other part of the enclosure. For I6, we coded when she was within one body-length of the contact mesh and if she was manipulating a woodchip or not.

\section{Results}

A total of 76 instances of object manipulation were observed in the video footage of ten sessions (totalling five hours; Table 2). First, we provide a detailed description of the sequence of events and then report the results of the video analyses carried out to support our observations.

\section{Table 2.}

Summary of recorded woodchip events, detailing the number of woodchip manipulations as well as 'retrieve, show, manipulate' sequences (shown in Figure 1) with the initiating individual.

\begin{tabular}{lcccc}
\hline Date & $\begin{array}{c}\text { Woodchip } \\
\text { manipulation }\end{array}$ & $\begin{array}{c}\text { Initiating 'retrieve, } \\
\text { show, manipulate' } \\
\text { sequences }\end{array}$ & $\begin{array}{c}\text { Non-initiator watching at } \\
\text { least once during } \\
\text { a sequence }\end{array}$ \\
\cline { 3 - 4 } & & I5 & I6 & \\
\hline June 17, 2019 & 3 & 0 & 0 & 0 \\
June 18, 2019 & 4 & 0 & 0 & 0 \\
June 19, 2019 & 31 & 19 & 0 & 15 \\
June 20, 2019 & 21 & 20 & 0 & 19 \\
June 21, 2019 & 14 & 13 & 0 & 0 \\
June 24, 2019 & 0 & 0 & 0 & 0 \\
June 26, 2019 & 0 & 0 & 0 & 2 \\
June 27, 2019 & 3 & 1 & 1 & 0 \\
June 28, 2019 & 0 & 0 & 0 & 0 \\
July 2, 2019 & 0 & 0 & 0 & 0 \\
\hline
\end{tabular}

For all 'retrieve, show, manipulate' sequences we note if the non-initiator watched at least once $(>2 s)$. 


\subsection{Sequence of events}

Six minutes after the curiosity panels were placed in E6 for the first session, I5 retrieved a woodchip from the ground and jumped up to a branch next to the mesh (within one body length) which separated the two enclosures. I5 looked at the woodchip and turned it around in her hand, then bit it. I6 oriented her attention to I5 and came over to the mesh, observing I5. After six seconds, I6 jumped away and scent marked the branch she was on. I5 continued to manipulate it for six seconds and then let it go and the woodchip fell to the floor. Ten minutes later, a very similar sequence occurred, then again, another 40 seconds later.

In the second session, again the same sequence occurred three times. It happened again, but I5 took the woodchip to the front of the enclosure (rather than the border between the two enclosures) and held the woodchip up to the mesh, then continued to bite and manipulate it.

The third session had the most woodchip manipulation (31 instances). In this session, I5 began bringing the woodchips to the border that separated the two individuals and holding them up against the mesh before or while manipulating the woodchip, the 'retrieve, show, manipulate' sequence (Figure 1; supplementary video A1 at https://doi.org/10.6084/m9.figshare. 13213700.v1). I5 also seemed to bite or scratch away at the woodchips until they became pointy on one side (see Figure 3). In this session, I5 also began to drop woodchips onto the table in her enclosure and subsequently returned to smell, touch, or retrieve them.

In the fourth session, I6 was actively involved with the woodchips for the first time. I5 brought a woodchip to the mesh and held it up momentarily and manipulated it as she was previously. I6 came over (within one body-length)
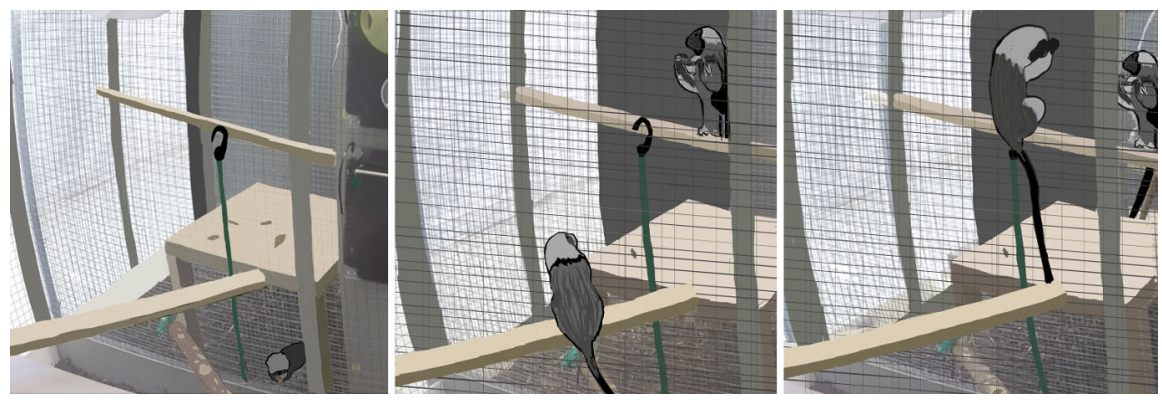

Figure 1. I6 watching I5 in the 'retrieve, show manipulate' sequence. 


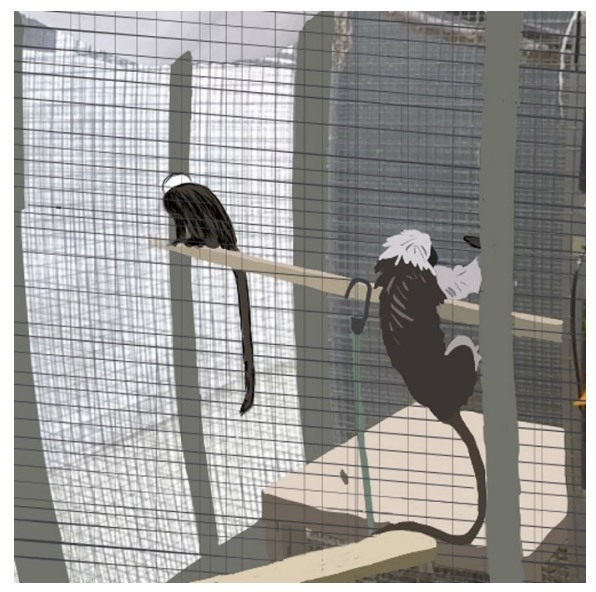

Figure 2. I6 pulling the woodchip from E5.

and watched. I5 then wedged the woodchip into the mesh and jumped out of view. I6 inspected the woodchip, jumped away, and then jumped back. I6 then grabbed the woodchip and tried to pull the woodchip out of the mesh and into her own enclosure (Figure 2; supplementary video A2 at https://doi. org/10.6084/m9.figshare.13213700.v1). I5 came back into view but turned her back. I6 continued to try to retrieve the woodchip and finally succeeded, taking the woodchip with her out of view. I5 looked at the mesh (where the woodchip used to be) and jumped out of view in a similar direction to I6.

In the final session with the panel in E6, similar activity occurred (retrieve, show, manipulate sequences). At one point, I5 left one of her woodchips on a branch near the mesh. I6 noticed and came over (within one body length), sticking her hand through the mesh and reaching for the woodchip, but she did not succeed. In another instance, I6 watched I5 as she sifted through woodchips on the floor before retrieving one and starting to manipulate it.

The panels were then moved to E5. In the first and second sessions no manipulation was observed. In the third session, I5 initiated the retrieve, show, manipulate sequence. Less than a minute later, I6 came into view with a woodchip for the first time. She held it momentarily then manipulated and bit it, then walked out of view with the woodchip in hand. I6 returned five seconds later and came over to the mesh and initiated the retrieve, show, manipulate sequence that I5 was previously doing (supplementary video A3 at https://doi.org/10.6084/m9.figshare.13213700.v1). I5 came over to the border (within one body-length) and watched while pacing back and forth on 

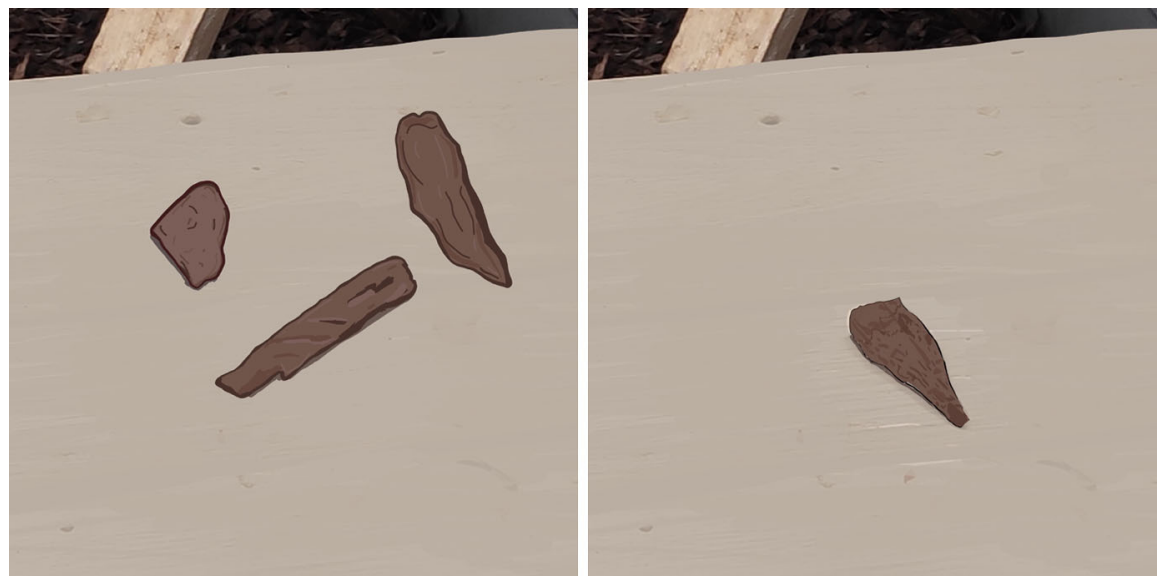

Figure 3. 'Regular' woodchips (left) and manipulated 'pointy' woodchip (right) found on table in the enclosure.

a nearby branch. I6 then dropped the woodchip and both I5 and I6 quickly jumped down to lower branches and directed their attention to the woodchip on the floor.

In the next session, we observed I6 sifting through woodchips on the floor, but no further action was recorded. Nothing occurred in the final session. Two days after the final session a pointy woodchip was found on the table in E5 (Figure 3).

Since July 2019 there have been multiple observations of woodchip manipulation in the main tamarin enclosure (where I5 and I6 were housed before being permanently removed) including searching for woodchips on the floor, picking them up and carrying them around as well as handling woodchips. Additionally, we found another 'pointy' woodchip in the main tamarin enclosure.

\subsection{Video analyses}

Of the five hours, 24 minutes and 15 seconds ( $8.08 \%$ of the total time) were spent on woodchip manipulation (by I5 and I6), in 76 instances with an average bout length of 21 seconds. Out of the 76 instances of object manipulation, only two were carried out by I6. I5 was the first individual to be observed manipulating woodchips and showing them to her neighbour (I6). I5 carried out $86.46 \%$ of her object manipulations at the contact mesh (between E5 and E6), $7.65 \%$ at the mesh at the front of the enclosure, and $5.89 \%$ elsewhere 


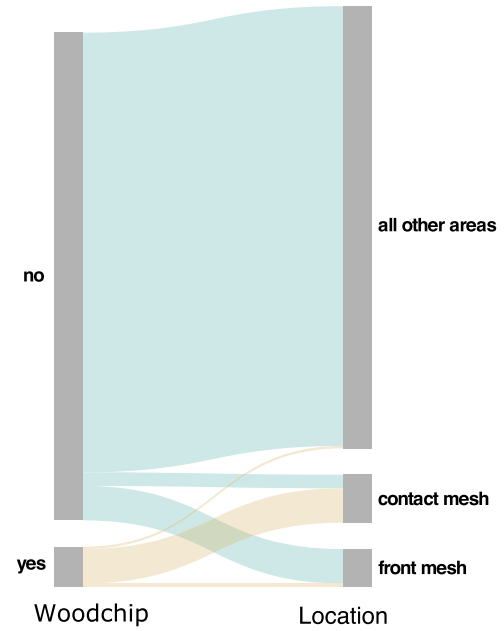

\begin{tabular}{lcc}
\hline Location I5 & $\begin{array}{c}\text { With } \\
\text { woodchip }\end{array}$ & $\begin{array}{c}\text { Without } \\
\text { woodchip }\end{array}$ \\
\hline At contact mesh & $00: 19: 35$ & $00: 07: 44$ \\
between E5 \& E6 & $6.528 \%$ & $2.578 \%$ \\
At front mesh & $00: 01: 44$ & $00: 19: 33$ \\
of E5 & $0.578 \%$ & $6.517 \%$ \\
Any other & $00: 01: 20$ & $04: 10: 03$ \\
area in E5 & $0.444 \%$ & $83.355 \%$ \\
\hline
\end{tabular}

Figure 4. Time spent in different locations of the enclosure by I5, when she was with vs. without woodchip. The percentages are relative to the total observation time (5:00:00).

(illustrated in Figure 4). This contrasts strongly with where she spent time when she was not manipulating the woodchip, which was almost exclusively in any area other than the contact mesh (97.21\%). Overall I5 spent $7.55 \%$ of the total observation period ( 5 hours) manipulating the woodchip. In comparison I6 only spent $0.53 \%$ of her time manipulating the woodchip, and only did so at the contact mesh but never in other areas of the enclosure. I6 spent $13.06 \%$ of the total observation time at the contact mesh. The vast majority of time at the contact mesh was spent without woodchip manipulation (95.92\%), the predominant behaviour was observing I5 (where she watched all but 5 of the 53 retrieve-show-manipulation sequences initiated by I5).

\section{Discussion}

We observed two captive cotton-top tamarins engaging in a woodchip manipulation innovation. Our analysis of these events suggests that, (i) the innovation was non-functional and arbitrary, (ii) the innovation was actively shared, and (iii) the innovation spread in the group.

First, the innovation was not observed in our colony before, even though both the tamarins and common marmosets are housed with the same woodchip flooring and have ample experience with this material. The behaviour does not serve an obvious function, such as foraging for gum, since tamarins 
do not have the anatomical adaptations to extract and digest large amounts of exudates (Garber, 1993; Schröpel, 2010) whereas marmosets do but never showed the behaviour. Alternatively, the manipulation of the woodchip may contribute to the development of motor skills, dexterity, and an understanding of physical causation - the precursors of tool-use (Kahrs \& Lockman, 2014). However, since the behaviour was performed by adult individuals and was never observed in immatures, this alternative is unlikely. Object manipulation has been assumed to be a precursor of tool-use (Parker, 1974; Parker \& Gibson, 1977; Kahrs \& Lockman, 2014), and the complexity of object manipulation has coevolved with terrestrially and brain size in primates (Meulman et al., 2012; Heldstab et al., 2016). Not surprisingly, there is but one reported description of wild, spontaneous tool-use in the small brained arboreal family of callitrichidae (consisting of marmosets and tamarins), namely in black lion tamarins (Kaisin et al., 2020). Nevertheless, there are several reports of learned tool-use in captive settings. Tamarins not only use various artificial objects to reach for food or groom conspecifics, but also seem to be able to understand the functionality of tools (Hauser et al., 1999, 2002; Stoinski \& Beck, 2001; Santos et al., 2003, 2005). Together, this suggests that that tamarins may have some bias toward object manipulation, especially in comparison to marmosets.

Second, the innovation appears to be actively shared (i.e., initiated by the innovator, without previous requests by the observer; term used analogous to the food sharing literature e.g., Brown et al., 2004; Jaeggi et al., 2010; Guerreiro Martins et al., 2019) by one individual (I5) who performed the vast majority of manipulations. I5 almost exclusively manipulated the woodchip at the contact mesh between the two enclosures, where she could be observed by her conspecific, rather than in any other location within the home enclosure. Specifically, of the total time spent manipulating the woodchip by I5, $86.46 \%$ was spent at the contact mesh. This is in stark contrast to the $2.79 \%$ of the time she spent in this location when she was without a woodchip. The preference to manipulate the woodchip on the perch at the contact mesh was thus not a mere side-effect of a general preference for that location (e.g., to receive social support, since the individuals were temporarily housed individually). Likewise, it was not a by-product of the need for physical support to manipulate the woodchip, because I5 had the same opportunity for physical support on the perch at the front of the enclosure (see Figure 2, individual sitting in the background). Nevertheless, when I5 was at the front mesh (21 
minutes and 17 seconds) she only spent $8.14 \%$ of that time manipulating woodchips, compared to when she was at the contact mesh (a total of 27 minutes and 19 seconds) where she spent $71.69 \%$ of that time manipulating woodchips. Together, this evidence shows a clear preference to manipulate the woodchip where it was best visible to the partner and suggests that the most parsimonious interpretation of the behaviour presented by I5 is active showing.

Third, the behaviour apparently spread through the group. Even though this short report does not provide any quantitative or formal evidence for social learning, the behaviour corresponds to 'peering' (described as directly looking at another individual's activity from a close range) which is considered as a proxy for observational social learning, e.g., in orang-utans (Schuppli et al., 2016). Moreover, the individuals in the main tamarin enclosure have been observed to manipulate wood chips on multiple occasions since the end of the study. It is possible that any individual from the main tamarin enclosure was the initial 'innovator' of this behaviour and it spread to I5 prior to her permanent removal from the main enclosure; it is equally likely that I5 was the innovator and other individuals from the main tamarin group learned from her, when she was still part of the main tamarin group or during the time she had occasional contact with the main group before being permanently separated. Regardless of the order of innovation and specific pattern of spread through the group, the mere fact that multiple individuals started to engage in a behaviour that was never observed in the entire colony strongly suggests it spread via social learning. This conclusion is consistent with ample reports of social learning in cotton-top tamarins (e.g., Moscovice \& Snowdon, 2006; Humle \& Snowdon, 2008; Dillis et al., 2010; Snowdon \& Roskos, 2017).

Cooperatively breeding callitrichid monkeys are known to have the motivational underpinnings to share information - their social system necessitates high levels of cooperation, including routine proactive food sharing; this propensity to share information is arguably even reflected in their vocal communication (Burkart et al., 2018). Recently an analysis of the prosocial behaviours of common marmosets (including their performance in cooperative tasks or their food sharing behaviour) provided evidence that marmoset prosociality fulfils the criteria of intentional behaviour, established by primate communication research (Burkart \& van Schaik, 2020). If prosocial behaviours are under potential intentional control, it may well be that active 
object sharing as a form of sharing information is similarly intentional. One commonly used criterion for intentional communication is sensitivity to the attentional state of the recipient (Townsend et al., 2017). We observed several times that I5 would stop showing the woodchip to I6 when she could see that I6 was not attentive (see supplementary video A4 at https://doi.org/10.6084/ m9.figshare.13213700.v1). Regardless, this anecdote cannot provide the evidence necessary to fully support the claim of intentional control over the showing behaviour, which would be a worthwhile course for future studies.

An alternative interpretation to information sharing could be intentional object presentation which has been found in another cooperatively breeding species, the Arabian babblers (Turdoides squamiceps). The object presentations in babblers are used as a form of intentional communication in a sexual context, namely, to initiate concealed copulations (Ben Mocha \& Pika, 2019). The lack of sexual context in the case of object showing presented in this paper, especially since these behaviours occurred between two twin sisters, makes this alternative explanation highly unlikely.

Curiously we observed the innovation first when the individuals were housed individually (but note that we cannot exclude the alternative that the behaviour was already present when I5 was still part of the main tamarin group, see above). It is possible that this housing situation enhanced the so called 'captivity effect' where the decrease of energy needed for foraging, vigilance, and overall survival coupled with an increase in free time leads to increased curiosity and motivation to approach or manipulate novel objects (Forss et al., 2015; Damerius et al., 2017; van Schaik et al., 2017). Cottontop tamarins are generally highly neophobic (Day et al., 2003), and perhaps combined with the lack of social interaction the captivity effect manifested slightly differently here, providing the motivation to manipulate a very familiar object in a novel way, and use it to attract the neighbour's attention.

Taken together, our observations suggest active sharing of a novel, arbitrary innovation in cotton-top tamarins. This may implicate that cotton-top tamarins show cultural variations in their behaviour. This potential for cultural variation has predominantly been studied in great apes (e.g., Whiten et al., 1999; van Schaik et al., 2003) but could be an interesting focus for future studies in the family of callitrichidae. Our anecdote provides evidence that such studies should include a special focus on factors such as social learning and/or active information sharing. 


\section{Acknowledgements}

Samin Gokcekus and Rahel K. Brügger are co-first authors. We would like to thank Gisep Bazzell for animal care-taking and support during data collection, Sandro Sehner for providing helpful insights on tamarin behaviour, and Anita Medik and Ferhat Yesilada for producing the figures.

\section{References}

Amici, F., Caicoya, A.L., Majolo, B. \& Widdig, A. (2020). Innovation in wild Barbary macaques (Macaca sylvanus). - Sci. Rep. 10: 4597.

Ben Mocha, Y. \& Pika, S. (2019). Intentional presentation of objects in cooperatively breeding Arabian babblers (Turdoides squamiceps). — Front. Ecol. Evol. 7. DOI:10.3389/fevo. 2019.00087.

Bonnie, K.E. \& de Waal, F.B.M. (2006). Affiliation promotes the transmission of a social custom: handclasp grooming among captive chimpanzees. — Primates 47: 27-34.

Bonnie, K.E., Horner, V., Whiten, A. \& de Waal, F.B.M. (2007). Spread of arbitrary conventions among chimpanzees: a controlled experiment. — Proc. Roy. Soc. Lond. B: Biol. Sci. 274: 367-372.

Brown, G.R., Almond, R.E.A. \& van Bergen, Y. (2004). Begging, stealing, and offering: food transfer in non-human primates. - Adv. Study. Behav. 34: 265-295.

Burkart, J.M., Guerreiro Martins, E., Miss, F. \& Zürcher, Y. (2018). From sharing food to sharing information: cooperative breeding and language evolution. — Interact. Stud. 19: 136-150.

Burkart, J.M. \& van Schaik, C.P. (2020). Marmoset prosociality is intentional. - Anim. Cogn. 23: 581-594.

Caldwell, C.A., Renner, E. \& Atkinson, M. (2018). Human teaching and cumulative cultural evolution. - Rev. Philos. Psychol. 9: 751-770.

Castro, L. \& Toro, M.A. (2014). Cumulative cultural evolution: the role of teaching. J. Theor. Biol. 347: 74-83.

Damerius, L.A., Forss, S.I., Kosonen, Z.K., Willems, E.P., Burkart, J.M., Call, J., Galdikas, B.M., Liebal, K., Haun, D.B. \& Van Schaik, C.P. (2017). Orientation toward humans predicts cognitive performance in orang-utans. - Sci. Rep. 7: 1-12.

Day, R.L., Coe, R.L., Kendal, J.R. \& Laland, K.N. (2003). Neophilia, innovation and social learning: a study of intergeneric differences in callitrichid monkeys. - Anim. Behav. 65: 559-571.

Dillis, C., Humle, T. \& Snowdon, C.T. (2010). Socially biased learning among adult cottontop tamarins (Saguinus oedipus). - Am. J. Primatol. 72: 287-295.

Forss, S.I., Schuppli, C., Haiden, D., Zweifel, N. \& Van Schaik, C.P. (2015). Contrasting responses to novelty by wild and captive orangutans. - Am. J. Primatol. 77: 1109-1121.

Garber, P.A. (1993). Seasonal patterns of diet and ranging in two species of tamarin monkeys: stability versus variability. — Int. J. Primat. 14: 145-166. 
Gokcekus, S. (2020). Behavioral flexibility, curiosity, and cooperative breeding: dealing with complex concepts and paradigms. Master Thesis, Durham University, Durham.

Guerreiro Martins, E.M., Moura, A.C. de A., Finkenwirth, C., Griesser, M. \& Burkart, J.M. (2019). Food sharing patterns in three species of callitrichid monkeys (Callithrix jacchus, Leontopithecus chrysomelas, Saguinus midas): individual and species differences. - J. Comp. Pscyhol. 133: 474-487.

Gunst, N., Huffman, M. \& Leca, J.-B. (2007). Japanese macaque cultures: inter- and intratroop behavioural variability of stone handling patterns across 10 troops. - Behaviour 144: 251-281.

Hauser, M.D., Kralik, J. \& Botto-Mahan, C. (1999). Problem solving and functional design features: experiments on cotton-top tamarins, Saguinus oedipus oedipus. - Anim. Behav. 57: 565-582.

Hauser, M.D., Santos, L.R., Spaepen, G.M. \& Pearson, H.E. (2002). Problem solving, inhibition and domain-specific experience: experiments on cottontop tamarins, Saguinus oedipus. — Anim. Behav. 64: 387-396.

Heldstab, S.A., Kosonen, Z.K., Koski, S.E., Burkart, J.M., van Schaik, C.P. \& Isler, K. (2016). Manipulation complexity in primates coevolved with brain size and terrestriality. - Sci. Rep. 6. https://doi.org/10.1038/srep24528.

Hobaiter, C., Poisot, T., Zuberbühler, K., Hoppitt, W. \& Gruber, T. (2014). Social network analysis shows direct evidence for social transmission of tool use in wild chimpanzees. PLoS Biol. 12: e1001960.

Huebner, F. \& Fichtel, C. (2015). Innovation and behavioral flexibility in wild redfronted lemurs (Eulemur rufifrons). — Anim. Cogn. 18: 777-787.

Humle, T. \& Snowdon, C.T. (2008). Socially biased learning in the acquisition of a complex foraging task in juvenile cottontop tamarins, Saguinus oedipus. - Anim. Behav. 75: 267277.

Jaeggi, A.V., Burkart, J.M. \& van Schaik, C.P. (2010). On the psychology of cooperation in humans and other primates: combining the natural history and experimental evidence of prosociality. — Philos. Trans. R. Soc. Lond. B: Biol. Sci. 365: 2723-2735.

Kahrs, B.A. \& Lockman, J.J. (2014). Building tool use from object manipulation: a perception-action perspective. - Ecol. Psychol. 26: 88-97.

Kaisin, O., Amaral, R.G., Bufalo, F.S., Brotcorne, F. \& Culot, L. (2020). Spontaneous tool use by a wild black lion tamarin (Leontopithecus chrysopygus). — Int. J. Primat. 41: 559-561.

Kendal, R.L., Coe, R.L. \& Laland, K.N. (2005). Age differences in neophilia, exploration, and innovation in family groups of callitrichid monkeys. - Am. J. Primatol. 66: 167-188.

Laidre, M.E. (2008). Do captive mandrills invent new gestures? - Anim. Cogn. 11: 179-187.

Leca, J.-B., Gunst, N. \& Huffman, M. (2011). Complexity in object manipulation by Japanese macaques (Macaca fuscata): a cross-sectional analysis of manual coordination in stone handling patterns. — J. Comp. Psychol. 125: 61-71.

Leca, J.-B., Gunst, N. \& Huffman, M.A. (2008). Of stones and monkeys: testing ecological constraints on stone handling, a behavioral tradition in Japanese macaques. - Am. J. Phys. Anthropol. 135: 233-244. 
Lonsdorf, E.V., Bonnie, K.E., Grim, M., Krupnick, A., Prestipino, M. \& Whyte, J. (2016). Seeding an arbitrary convention in capuchin monkeys: the effect of social context. Behaviour 153: 633-654.

Meulman, E.J.M., Sanz, C.M., Visalberghi, E. \& van Schaik, C.P. (2012). The role of terrestriality in promoting primate technology. — Evol. Anthropol. 21: 58-68.

Moscovice, L.R. \& Snowdon, C.T. (2006). The role of social context and individual experience in novel task acquisition in cottontop tamarins, Saguinus oedipus. - Anim. Behav. 71: 933-943.

Navarrete, A.F., Reader, S.M., Street, S.E., Whalen, A. \& Laland, K.N. (2016). The coevolution of innovation and technical intelligence in primates. - Philos. Trans. R. Soc. Lond. B; Biol. Sci. 371: 20150186.

Ottoni, E.B. \& Izar, P. (2008). Capuchin monkey tool use: overview and implications. Evol. Anthropol. 17: 171-178.

Parker, C.E. (1974). Behavioral diversity in ten species of nonhuman primates. - J. Comp. Physiol. 87: 930-937.

Parker, S.T. \& Gibson, K.R. (1977). Object manipulation, tool use and sensorimotor intelligence as feeding adaptations in cebus monkeys and great apes. - J. Hum. Evol. 6: 623-641.

Perry, S. (2011). Social traditions and social learning in capuchin monkeys (Cebus). — Philos. Trans. R. Soc. Lond. B: Biol. Sci. 366: 988-996.

Perry, S., Panger, M., Rose, L.M., Baker, M., Gros-Louis, J., Jack, K., Mackinnon, K.C., Manson, J., Fedigan, L. \& Pyle, K. (2003). Traditions in wild white-faced capuchin monkeys. - In: The biology of traditions, 1st edn (Fragaszy, D.M. \& Perry, S., eds). Cambridge University Press, Cambridge, p. 391-425.

Perry, S.E., Barrett, B.J. \& Godoy, I. (2017). Older, sociable capuchins (Cebus capucinus) invent more social behaviors, but younger monkeys innovate more in other contexts. Proc. Natl. Acad. Sci. USA 114: 7806-7813.

Rapaport, L.G. (2011). Progressive parenting behavior in wild golden lion tamarins. - Behav. Ecol. 22: 745-754.

Rapaport, L.G. \& Ruiz-Miranda, C.R. (2002). Tutoring in wild golden lion tamarins. — Int. J. Primatol. 23: 1063-1070.

Reader, S.M. \& Laland, K.N. (2001). Primate innovation: sex, age and social rank differences. - Int. J. Primatol. 22: 787-805.

Santorelli, C.J., Schaffner, C.M., Campbell, C.J., Notman, H., Pavelka, M.S., Weghorst, J.A. \& Aureli, F. (2011). Traditions in spider monkeys are biased towards the social domain. PLoS ONE 6: e16863.

Santos, L.R., Miller, C.T. \& Hauser, M.D. (2003). Representing tools: how two non-human primate species distinguish between the functionally relevant and irrelevant features of a tool. - Anim. Cogn. 6: 269-281.

Santos, L.R., Rosati, A., Sproul, C., Spaulding, B. \& Hauser, M.D. (2005). Means-meansend tool choice in cotton-top tamarins (Saguinus oedipus): finding the limits on primates' knowledge of tools. - Anim. Cogn. 8: 236-246. 
Schröpel, M. (2010). Neuweltprimaten Band 1: Krallenaffen. — Books on Demand, Regensdorf.

Schuppli, C., Meulman, E.J., Forss, S.I., Aprilinayati, F., van Noordwijk, M.A. \& van Schaik, C.P. (2016). Observational social learning and socially induced practice of routine skills in immature wild orang-utans. — Anim. Behav. 119: 87-98.

Snowdon, C.T. \& Roskos, T.R. (2017). Stick-weaving: innovative behavior in tamarins (Saguinus oedipus). — J. Comp. Psychol. 131: 174-178.

Stoinski, T.S. \& Beck, B.B. (2001). Spontaneous tool use in captive, free-ranging golden lion tamarins (Leontopithecus rosalia rosalia). — Primates 42: 319-326.

Townsend, S.W., Koski, S.E., Byrne, R.W., Slocombe, K.E., Bickel, B., Boeckle, M., Braga Goncalves, I., Burkart, J.M., Flower, T., Gaunet, F., Glock, H.J., Gruber, T., Jansen, D.A.W.A.M., Liebal, K., Linke, A., Miklósi, Á., Moore, R., van Schaik, C.P., Stoll, S., Vail, A., Waller, B.M., Wild, M., Zuberbühler, K. \& Manser, M.B. (2017). Exorcising Grice's ghost: an empirical approach to studying intentional communication in animals. - Biol. Rev. 92: 1427-1433.

Troisi, C.A., Hoppitt, W.J.E., Ruiz-Miranda, C.R. \& Laland, K.N. (2018). Food-offering calls in wild golden lion tamarins (Leontopithecus rosalia): evidence for teaching behavior? Int. J. Primatol. 39: 1105-1123.

Troisi, C.A., Hoppitt, W.J.E., Ruiz-Miranda, C.R. \& Laland, K.N. (2020). The role of food transfers in wild golden lion tamarins (Leontopithecus rosalia): support for the informational and nutritional hypothesis. — Primates. https://doi.org/10.1007/s10329-02000835-0.

van Leeuwen, E.J.C., Cronin, K.A. \& Haun, D.B.M. (2014). A group-specific arbitrary tradition in chimpanzees (Pan troglodytes). - Anim. Cogn. 17: 1421-1425.

van Schaik, C.P., Ancrenaz, M., Borgen, G., Galdikas, B., Knott, C.D., Singleton, I., Suzuki, A., Utami, S.S. \& Merrill, M. (2003). Orangutan cultures and the evolution of material culture. - Science 299: 102-105.

van Schaik, C.P., Pradhan, G.R. \& Tennie, C. (2019). Teaching and curiosity: sequential drivers of cumulative cultural evolution in the hominin lineage. - Behav. Ecol. Sociobiol. 73: 2.

van Schaik, C.P., Forss, S. \& Damerius, L. (2017). How the origin of curiosity may have boosted hominin cultural evolution. - Am. J. Phys. Anthropol. 162: 391.

Whiten, A., Goodall, J., McGrew, W.C., Nishida, T., Reynolds, V., Sugiyama, Y., Tutin, C.E.G., Wrangham, R.W. \& Boesch, C. (1999). Cultures in chimpanzees. - Nature 399: 682-685.

Whiten, A., Goodall, J., McGrew, W.C., Nishida, T., Reynolds, V., Sugiyama, Y., Tutin, C.E.G., Wrangham, R.W. \& Boesch, C. (2001). Charting cultural variation in chimpanzees. - Behaviour 138: 1481-1516.

Whiten, A. \& van Schaik, C.P. (2007). The evolution of animal 'cultures' and social intelligence. - Philos. Trans. R. Soc. Lond. B: Biol. Sci. 362: 603-620.

Wich, S.A., Krützen, M., Lameira, A.R., Nater, A., Arora, N., Bastian, M.L., Meulman, E., Morrogh-Bernard, H.C., Atmoko, S.S.U., Pamungkas, J., Perwitasari-Farajallah, D., 
Hardus, M.E., van Noordwijk, M. \& van Schaik, C.P. (2012). Call cultures in orangutans? - PLoS ONE 7: e36180.

Wrangham, R.W., Koops, K., Machanda, Z.P., Worthington, S., Bernard, A.B., Brazeau, N.F., Donovan, R., Rosen, J., Wilke, C., Otali, E. \& Muller, M.N. (2016). Distribution of a chimpanzee social custom is explained by matrilineal relationship rather than conformity. Curr. Biol. 26: 3033-3037. 